\title{
Longitudinal Assessment of Web-enabled Muddiest Points in Different Biomed- ical Engineering Courses
}

\section{Dr. Casey Jane Ankeny, Arizona State University}

Casey J. Ankeny, PhD is lecturer in the School of Biological and Health Systems Engineering at Arizona State University. Casey received her bachelor's degree in Biomedical Engineering from the University of Virginia in 2006 and her doctorate degree in Biomedical Engineering from Georgia Institute of Technology and Emory University in 2012 where she studied the role of shear stress in aortic valve disease. Currently, she is investigating cyber-based student engagement strategies in flipped and traditional biomedical engineering courses. She aspires to understand and improve student attitude, achievement, and persistence in student-centered courses.

\section{Prof. Stephen J Krause, Arizona State University}

Stephen Krause is professor in the Materials Science Program in the Fulton School of Engineering at Arizona State University. He teaches in the areas of introductory materials engineering, polymers and composites, and capstone design. His research interests include evaluating conceptual knowledge, misconceptions and technologies to promote conceptual change. He has co-developed a Materials Concept Inventory and a Chemistry Concept Inventory for assessing conceptual knowledge and change for introductory materials science and chemistry classes. He is currently conducting research on NSF projects in two areas. One is studying how strategies of engagement and feedback with support from internet tools and resources affect conceptual change and associated impact on students' attitude, achievement, and persistence. The other is on the factors that promote persistence and success in retention of undergraduate students in engineering. He was a coauthor for best paper award in the Journal of Engineering Education in 2013. 


\section{Longitudinal Assessment of Web-enabled Muddiest Points in Different Biomedical Engineering Courses}

Research highlights the benefit of student reflection and frequent, formative feedback. One such method is the Muddiest Point exercise where students reflect after instruction about both unclear and interesting points. Then, instructors analyze student feedback for the most popular concepts and select those central to the learning objective. Previously, our work has shown that students feel favorably about the interest, utility, and "cost" associated with this exercise in a one-credit, junior level Statistics course. This work compares student attitude in other courses to discern if the Muddiest Point exercise strategy is universally favorable.

The previously validated, reliable Student Value Survey of Muddiest Points Survey by Carberry, et al. was used to assess student attitude about utility, interest, and "cost" of this student engagement strategy in the following required courses: biomaterials (BM), statistics (ST), and transport phenomena (TP). Briefly, transport phenomena is a three-credit, flipped course for juniors. Biomaterials is a traditionally-taught, four-credit course also at the junior level. After each lecture, students submitted both unclear and most interesting concepts through Blackboard. Following feedback, the instructor analyzed the results and created feedback using a different strategy than previously employed. At the midpoint and end of the semester, students participated in the Student Value Survey. Responses were on a Likert scale where 1 is strongly disagree and 4 is strongly agree. Data from multiple semesters (ST- 4 semesters, TP and BM 2 semesters) were analyzed. Percentages corresponding to agreement correlate to scores of " 3 " and "4". Differences were evaluated using the non-parametric Kruskal-Wallis test with post-hoc analysis. Previously, comparisons between mid- and end- of semester surveys yielded few differences; therefore, this analysis focuses on the post-semester data $\left(n_{B M}=26, n_{S T}=200\right.$, and $\left.\mathrm{n}_{\mathrm{TP}}=54\right)$.

Overall, students felt that the Muddiest Point exercise was interesting (72\%-BM, 62\%-ST, 65\%TP), useful (98\%-BM, 93\%-ST, 90\%-TP), and did not cost too much in terms of time and emotion (72\%-BM, 75\%-ST, 70\%-TP). Question-by-question investigation showed that students felt favorably with respect to all survey aspects and revealed small but statistically significant differences among classes. More specifically, students in biomaterials course felt that the Muddiest Point exercise "was an effective way to increase engagement in the course" more so than those in the statistics course. Further, students in the biomaterials and statistics courses felt that the Muddiest Point exercise allowed them to see "relevance of [the subject matter] to the real world" more so than those in the transport phenomena course. There were no other significant differences in question responses among classes. Further, statistical analysis confirmed that there were no differences in the overall categories of "utility", "interest", and "cost" (p>0.05) among the selected biomedical engineering classes.

This work highlights high student value of the Muddiest Point exercise in statistics, biomaterials, and transport phenomena courses. Moreover, these results suggest that the Muddiest Point exercise is an effective reflective tool for frequent, formative feedback in any classroom. 


\section{Introduction}

Frequent formative feedback in the form of the Muddiest Point (MP) exercise has proven to be an effective instructional tool. ${ }^{1-5}$ The original Muddiest Point exercise developed by Mosteller in 1988 asked students the following questions: 1) What was the most important point in lecture? 2) What was the muddiest? and 3) What would you like to hear more about ${ }^{6,7}$ In the past, Muddiest Points were collected by paper and pencil and more recently using the online system Concept Warehouse available through Oregon State University or through Blackboard.

The Muddiest and Most Interesting Points (MIP) exercise was implemented in three required, junior level classes of varying structure in biomedical engineering at a large public university: Introduction to Biomaterials (BM), Introduction to Statistics for Biomedical Engineers (ST), and Transport Phenomena for Biomedical Engineers (TP). Here, the students were asked which concepts were most unclear and most interesting.

- Biomaterials is a 4 credit, lecture-style class that has been shifting towards a studentcentered class. A 2.5-hour guided inquiry laboratory accompanies the two 75-minute lecture component. In lecture presently, the first 15 minutes are dedicated to the MIP activity. After which, students work in groups to create concept maps using CMap or MindMup, a web-based concept mapping program. During the last 30 minutes, new information is presented and students are asked to submit MIP through a Blackboard survey for participation credit.

- The statistics course is a flipped classroom and meets weekly for 50 minutes. Lectures are short ( $\sim 15$ minutes), online lectures delivered using a pencast. After watching the lecture, students complete a short homework assignment and submit MIP through Blackboard. During class sessions, the first 15 minutes are spent covering the MIP after which students work in teams to analyze biomedical data using both SPSS and MATLAB.

- Transport phenomena is a 3-credit flipped classroom where students watch 30-60 minute lectures and submit MIP feedback prior to class meetings. In class, 15 minutes are spent covering MIP followed by team-based problem solving sessions.

To prepare the MIP presentation, student feedback is collected anonymously shortly after watching the lecture through the classroom management platform Blackboard. Specifically, students are asked the following in a survey: 1) What is muddiest or most unclear?, 2) How muddy on a scale of $1-$ a little to 5-very, 3) What is most interesting?, and 4) How interesting on a scale of 1 -a little to 5--very? Then, the raw student quotes are inputted into a word cloud generator (Wordle.net). The resulting word cloud shows which words were most popular as the largest words. This allows for the instructor to quickly comb through hundreds of submissions for the muddiest and most interesting topics. Then, the most popular topics are compared to the learning objectives. Three to four of the most popular topics included in both the Muddiest Point and Most Interesting point sections which are also central to the learning objectives are then selected to cover. A new method or approach is used to cover the difficult concept. Commonly, short YouTube videos or additional examples are used. For example, in biomaterials, to assist with trouble in edge and screw dislocation, a segment from a YouTube video created by a 
professor at a different university was used. Students watched in the clips in groups followed by a brief class discussion. To assist with trouble determining the difference between paired and unpaired t-tests, a game was created where students were given several scenarios and asked to determine the appropriate test. Finally, an example of a MIP feedback strategy in transport phenomena where students are having with problems requiring reading graphs, the instructor worked through additional examples and then had the student teams complete another example before moving onto new material. At this time, the Most Interesting Points are included for general interest without adding additional material. Future research will include extending and evaluating activities based on the Most Interesting Points as well.

Previous research in a flipped, interactive statistics class showed that the Muddiest Point exercise was one of the most favored active learning strategies. ${ }^{5}$. Further, to date, most studies have investigated the effectiveness of MP exercises in a specific class ${ }^{5,8}$. This study investigates the effectiveness of the MP exercise in multiple class formats to suggest its suitability as an easy, effective teaching strategy in any classroom.

\section{Methods}

IRB approval (MOD00001667) was obtained to collect MIPs voluntarily and anonymously in three junior-level biomedical engineering courses: biomaterials (BM), statistics (ST), and transport phenomena (TP). For the flipped courses (ST and TP), feedback was submitted immediately after watching the lecture and for the in-class lecture course (BM), feedback was submitted with hours of instruction.

Longitudinal analysis of the MP component of the MIP exercise was completed using data from multiple semesters: 4 semesters for ST $(n=200)$ and 2 semesters for BM $(n=26)$ and TP $(n=54)$. Analysis included attitudinal and persistence assessment. Persistence was calculated as those students enrolled on the $21^{\text {st }}$ day of class and those taking the final. To assess student attitude, students completed the reliable, validated Student Value of Muddiest Point Survey at the midpoint and end of the semester. This is survey is based on motivation theory ${ }^{1}$ to assess the interest, utility, and cost of the instructional practice.

This attitudinal data was analyzed using non-parametric statistics, namely the Kruskal-Wallis test to look for differences in individual survey questions as well as the three main survey groups interest, utility, and "cost". Additionally, percent disagreement and agreement for survey statements was calculated; where, percent disagreement is the combined percentage of " 1 strongly disagree" and "2-disagree" responses and percent agreement is the combined percentage of 3-agree and 4-strongly agree responses.

\section{Results}

In all three classes, there was a favorable attitude regarding the interest, utility, and "cost" of the MP component of the MIP exercise. Overall, the highest positive attitude was the utility of the exercise (92\%), followed by the "cost" of the exercise (72\%), and the interest of the MP activity (67\%). More specifically, $72 \%, 63 \%$, and $65 \%$ of students in the BM, ST, and TP courses respectively felt that the activity was interesting. Moreover, the majority of the surveyed 
students in all classes felt that the activity was motivating (53\%), increased their engagement (74\%), helped them understand their own learning (68\%) and increased their responsibility $(71 \%)$. Percentages for individual courses $\left(n_{\mathrm{BM}}=26, \mathrm{n}_{\mathrm{ST}}=200\right.$, and $\left.\mathrm{n}_{\mathrm{TP}}=54\right)$ may be found in Table 1 below.

Additionally, 97\%, 92\%, and 88\% of students in the BM, ST, and TP courses respectively felt that the activity was useful. Overall, students felt that the material covered in the MP activity would be of use after graduation (90\%), will be useful in their career or future educational goals (90\%), and helped show the relevance of the course to the real world (97\%).

Lastly, the majority of the students in all three classes did not feel that the MP exercise was too "costly". In other words, $72 \%, 75 \%$, and $70 \%$ of the students in the BM, ST, and TP courses respectively did not feel that the MP exercise was too costly in terms of effort, time and emotion. More specifically, $71 \%$ of all surveyed students stated that the activity did not take too much effort. Sixty-nine percent of students felt that it did not make them anxious or frustrated. Finally, $77 \%$ of the students did not feel that the activity took too much time.

Table 1: Student Value of Muddiest Point Survey Results in Three Biomedical Engineering Courses (Biomaterials - BM, Statistics - ST, Transport Phenomena - TP)

\begin{tabular}{|l|r|r|l|}
\cline { 2 - 4 } \multicolumn{1}{|c|}{} & BM & ST & TP \\
\hline INTEREST/ATTAINMENT VALUE & & & \\
\hline motivated me to do well in the course & $\mathbf{5 4 \%}$ & $\mathbf{5 2 \%}$ & $\mathbf{5 3 \%}$ \\
\hline was an effective way to increase engagement & $\mathbf{8 9 \%}$ & $\mathbf{6 5 \%}$ & $\mathbf{6 7 \%}$ \\
\hline helped me better understand my own learning & $\mathbf{7 7 \%}$ & $\mathbf{6 4 \%}$ & $\mathbf{6 4 \%}$ \\
\hline increased my level of responsibility & $\mathbf{6 9 \%}$ & $\mathbf{6 9 \%}$ & $\mathbf{7 5 \%}$ \\
\hline & & & \\
\hline UTILITY VALUE & & & \\
\hline will be of value after graduation & $\mathbf{9 6 \%}$ & $\mathbf{8 9 \%}$ & $\mathbf{8 5 \%}$ \\
\hline will be useful in career and/or graduate school goals & $\mathbf{9 6 \%}$ & $\mathbf{9 0 \%}$ & $\mathbf{8 5 \%}$ \\
\hline helped me see relevance of course to the real word & $\mathbf{1 0 0 \%}$ & $\mathbf{9 6 \%}$ & $\mathbf{9 5 \%}$ \\
\hline & & & \\
\hline COST & & & \\
\hline did not required too much effort & $\mathbf{6 9 \%}$ & $\mathbf{7 3 \%}$ & $\mathbf{7 1 \%}$ \\
\hline did not make me frustrated and anxious & $\mathbf{6 9 \%}$ & $\mathbf{7 2 \%}$ & $\mathbf{6 7 \%}$ \\
\hline did not require too much time & $\mathbf{7 7 \%}$ & $\mathbf{8 1 \%}$ & $\mathbf{7 3 \%}$ \\
\hline
\end{tabular}

Statistical analysis yield few differences among student attitude when comparing individual survey question responses. The only statistically significant difference among classes pertaining to the MP interest regards the engagement category. Students in the Biomaterials (BM) course felt that the activity increased their engagement more so than the Statistics (ST) students $(\mathrm{p}=0.018)$ as shown in Figure 1. 


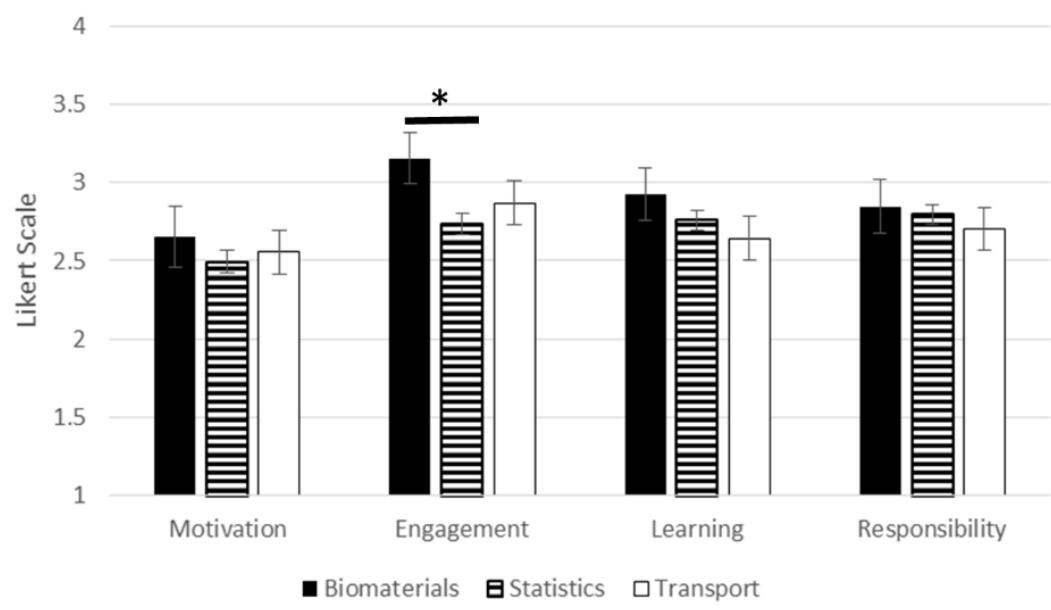

Figure 1: Student Interest Value of Muddiest Points in Three Biomedical Engineering Courses. The average interest score for the Muddiest Point component of the MIP activity is favorable. The only statistically significant difference among classes is an increase in the degree of engagement in biomaterials over statistics ( 1 - strongly disagree to 4-strong agree; $p=0.018$, $\mathrm{n}_{\mathrm{BM}}=26, \mathrm{n}_{\mathrm{ST}}=200$, and $\left.\mathrm{n}_{\mathrm{TP}}=54\right)$.

Moreover, there were only two statistically significant differences in student attitude regarding the utility of the MP exercise. More specifically, students in the BM course felt that the MP helped show the relevance of the course material to the real world more so than the TP students $(\mathrm{p}=0.012)$. Also, ST students felt that the MP showed the real world applications of the material more so than the TP students $(\mathrm{p}=0.028)$ as shown in Figure 2.

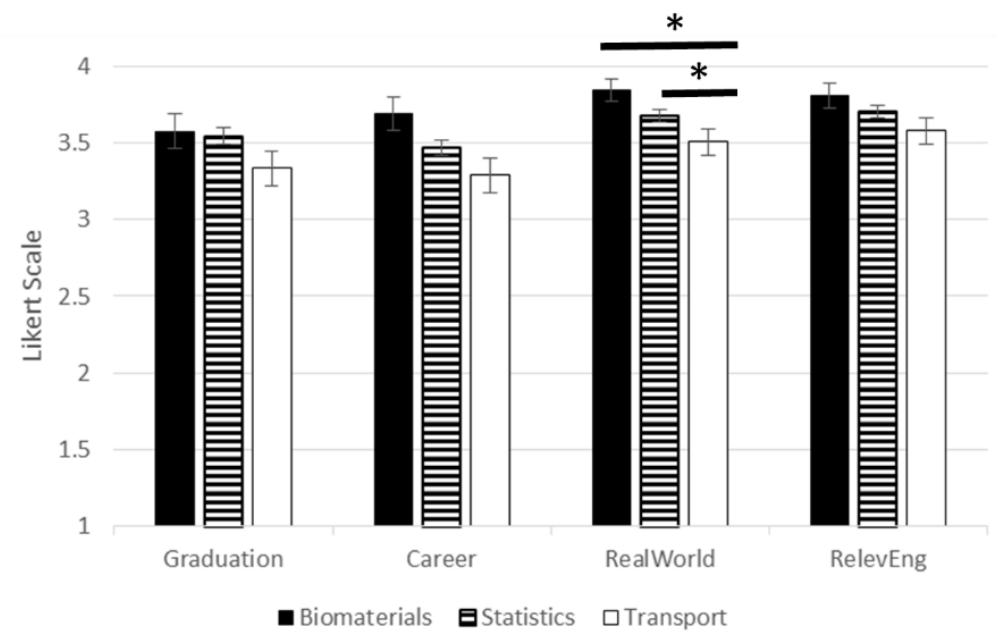

Figure 2: Student Utility Value of Muddiest Points in Three Biomedical Engineering Courses. The average utility score for the MP exercise is high with only a statistically significant difference in the agreement regarding the MP activities ability to tie course concepts to the real world. There is a statistically significant increase from the transport attitude as 
compared to the biomaterials $(\mathrm{p}=0.012)$ and the statistics $(\mathrm{p}=0.028)$ scores $(1-$ strongly disagree to 4-strong agree; $\mathrm{n}_{\mathrm{BM}}=26, \mathrm{n}_{\mathrm{ST}}=200$, and $\left.\mathrm{n}_{\mathrm{TP}}=54\right)$.

Statistical analysis of the cost associated with the MP exercise yielded no significant differences terms of students' opinion of the time, effort, and emotional costs of the MP activity as shown in Figure 3. Additionally, three survey groups, interest, utility, and cost were formed by averaging scores associated with questions which mapped during factor analysis. This overall analysis showed no statistically significant differences in the general survey groups among the three classes as depicted in Figure 4.

Persistence was high in all three classes. Percent averages of those enrolled on the $21^{\text {st }}$ day of classes and those present during the final are as follows: BM- 92\%, TP $-86 \%$, and ST $-98 \%$.

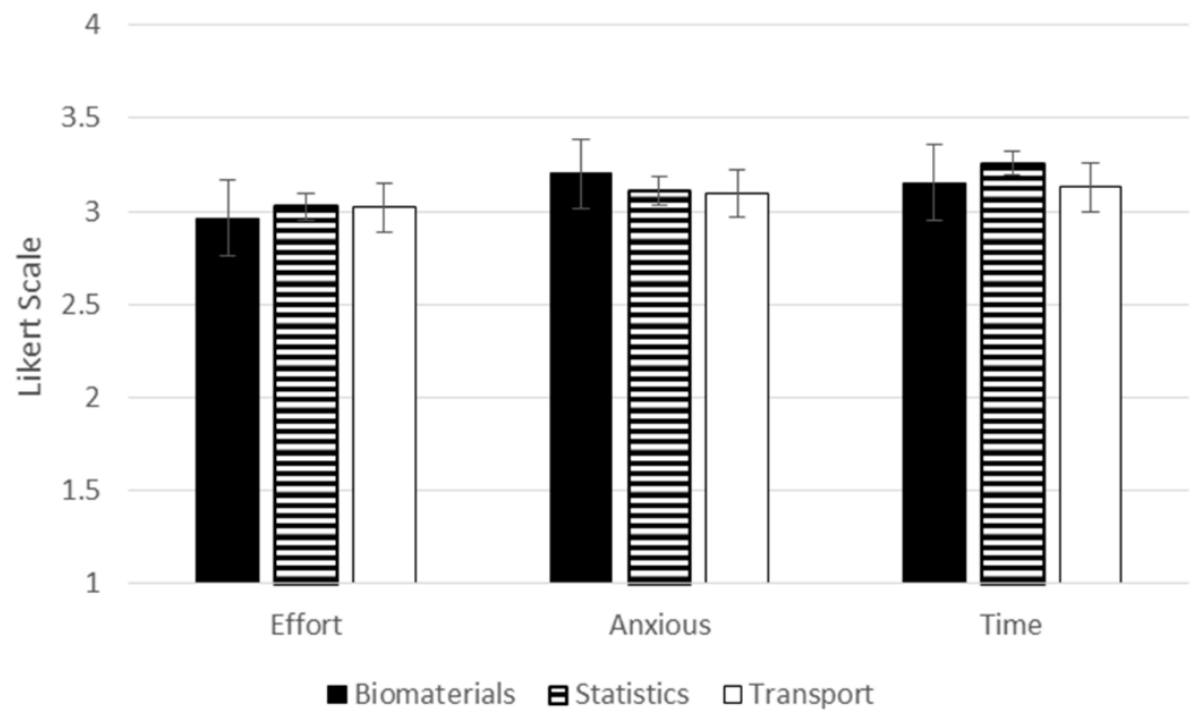

Figure 3: Student Attitude about "Cost" of Muddiest Points in Three Biomedical Engineering Courses. The average cost associated with the MP is appropriate. The average cost scores demonstrates that students did not feel the MP activity took too much effort, made them anxious, or took too much time ( 1 - strongly disagree to 4 -strong agree; $\mathrm{n}_{\mathrm{BM}}=26, \mathrm{n}_{\mathrm{ST}}=200$, and $\left.\mathrm{n}_{\mathrm{TP}}=54\right)$. 


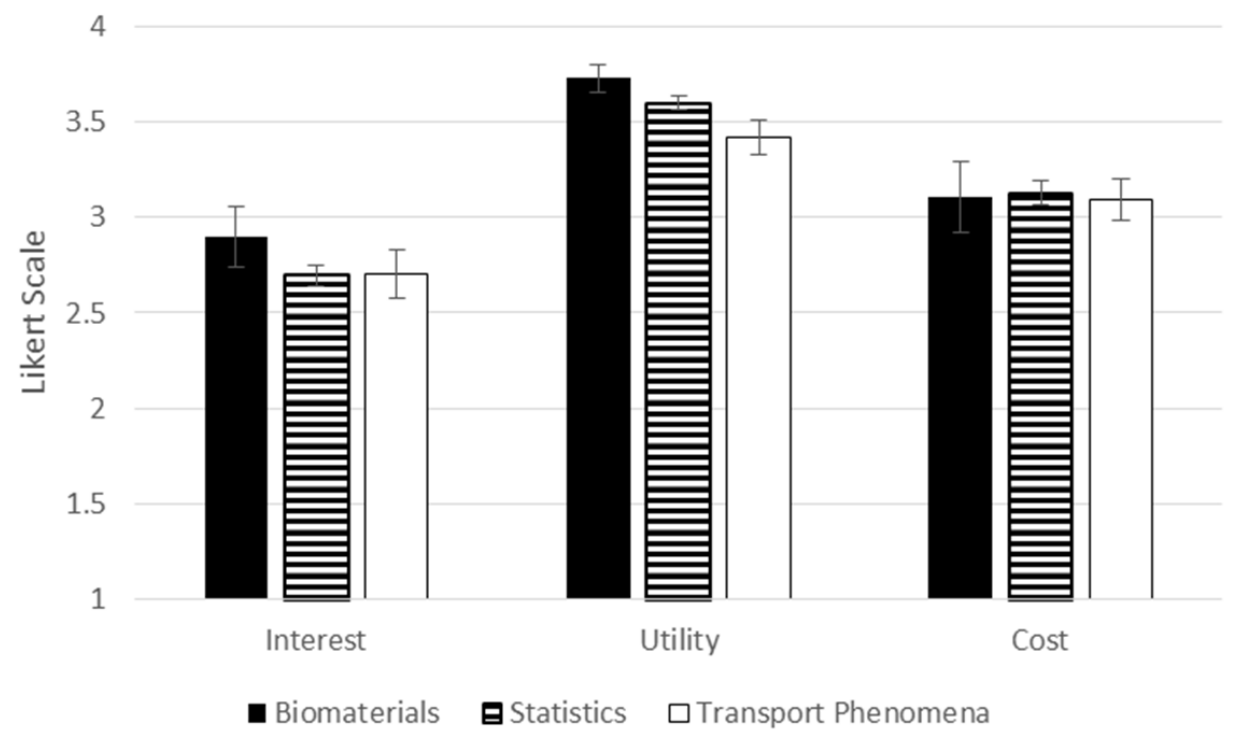

Figure 4: Comparison of Interest, Utility, and Cost of Muddiest Points among Three Biomedical Engineering Courses. There are no statistically significant differences among classes regarding the average interest, utility, and cost associated with the MP activity (1strongly disagree to 4 -strong agree; $\mathrm{n}_{\mathrm{BM}}=26, \mathrm{n}_{\mathrm{ST}}=200$, and $\mathrm{n}_{\mathrm{TP}}=54$ ).

\section{Discussion and Conclusion}

Statistical analysis showed that students place high value on the Muddiest Point exercise in terms of interest (92\% agreement), utility ( $72 \%$ agreement), and cost (67\% agreement).

There were few differences in student attitude among classes. Namely, there was an increase in student engagement due to the MP exercise in the biomaterials course versus the Statistics course. Further, there was a statistically significant decrease in student opinion about the MP activity's ability to relate the course concepts to the real world in the transport class versus the biomaterials and statistics courses. It is important that the responses are favorable in all cases. Future studies must be completed to determine the reason for these differences. In terms of engagement, one of the two Biomaterials courses assessed was approximately $25-30 \%$ of the normal class size (typically 100 students). This would allow for a greater percentage of the class to have its Muddiest Points covered therefore potentially increasing student engagement. In the transport course, there are several Biomedical Engineering (BME) examples; however, not all examples are directly related to the Biomedical Engineering. Future adaptations of these examples to show the real world significance to BME and related assessment will be completed to look for improvements in that aspect.

At this time, student achievement as a result of the Muddiest Point exercise has not been assessed. Because the instructor has always taught using Muddiest Points it is difficult to have a properly controlled experiment. Further, we are unable to retroactively collect achievement data and link because of anonymity. Additionally, using exam scores will be more of an indirect assessment than a direct assessment because concepts other than the Muddiest Point concepts are 
tested. In the future, we will analyze the MP feedback to look for the disappearance of confusing concepts. Additionally, we will create a muddiest point concept quiz to determine if we are able to alleviate Muddiest Points. More specifically, we will compare student scores related Muddiest Point concepts before and after the MP mini-lecture. Currently, the Most Interesting Points are only presented for general interest. Future work will consider expanding on these interesting points and evaluating student attitude and achievement based on the extension.

Due to the limited time of the instructor, it is essential to select instructional activities that are effective and time efficient. This study along with a related study of various engagement strategies shows a high value associated with the Muddiest Point intervention. ${ }^{5}$ Further, this work highlights high student value of the Muddiest Point exercise in classes with varying formats (flipped versus traditional, 1-credit vs. 3- or 4-credit, courses with more traditional length lectures versus courses with mini-lectures, and courses of varying subject matter). These results suggest that the Muddiest Point exercise is an effective reflective tool for frequent, formative feedback in any classroom.

\section{Acknowledgements}

The authors acknowledge the support of this work from NSF Grant \#1226325. 
1. Carberry A, Waters C, Krause S, Ankeny C. "Unmuddying” Course Content Using Muddiest Point Reflections. Front Educ. 2013;Oct 23-26:937-942.

2. Greer S. Teaching Cycle 1 : "Clearing the muddiest point" -. In: Teaching Cycle (PGCTHE Portfolio).; 2011:1-10.

3. King DB. Using Clickers To Identify the Muddiest Points in Large Chemistry Classes. J Chem Educ. 2011;88:1485-1488.

4. Carlson A. Classroom Assessment Technique: Muddiest Point. 2010. http://pandora.cii.wwu.edu/cii/resources/modules/muddiestpoint/default.asp.

5. Ankeny C, Krause S. Flipped Biomedical Engineering Classroom using Pencasts and Muddiest Point Webenabled Tools. In: American Society of Engineering Education. Indianapolis; 2014.

6. Mosteller F. The "Muddiest Point in the Lecture" as a Feedback Device. J Harvard-Danforth Cent. 1989;(April):10-21. http://isites.harvard.edu/fs/docs/icb.topic771890.files/OTL3-Mosteller-Muddiest.pdf.

7. Mosteller F. Broadening the Scope of Statistics and Statistical Education Broadening the Scope of Statistics and Statistical Education. Am Stat. 1988;42(2):93-99.

8. Krause S, Baker D, Carberry A, Koretsky M, Waters C. Muddiest Point Formative Feedback in Core Materials Classes with YouTube, Blackboard, Class Warm-ups and Word Clouds. Am Soc Eng Educ. 2013;ID7130. 